\title{
Membrana de látex da seringueira (Hevea brasiliensis), com e sem polilisina a 0,1\% e tela de marlex na reconstrução de defeitos iatrogênicos da parede abdominal de ratos $^{1}$
}

\author{
Seringueira's latex membrane (Hevea brasiliensis) with and without polylysine $0,1 \%$ \\ and marlex mesh for the reconstruction of iatrogenics abdominal wall defects in rats
}

\author{
Neusa Margarida Paulo², Flávia Gontijo de Lima³ , Juarez Távora de Siqueira Júnior4, Luiz Fernando Froes Fleury ${ }^{5}$, \\ Fabiano José Ferreira de Sant'Ana ${ }^{6}$, Alinne Cardoso Borges ${ }^{3}$, Thalita da Costa Telles ${ }^{3}$ \\ 1. Trabalho realizado no laboratório de cirurgia experimental da Escola de Veterinária da UFG. \\ 2. Professora Adjunto Doutora da disciplina de cirurgia veterinária e do programa de pós-graduação em Ciência Animal da Escola de \\ Veterinária da UFG. \\ 3. Acadêmicas da Escola de Veterinária da Universidade Federal de Goiás. \\ 4. Médico cirurgião geral e professor de anatomia humana do Instituto de Ciências Biológicas da UFG. \\ 5. Professor adjunto do Dep. de Patologia e Imunologia da Faculdade de Medicina da UFG. Mestre em Medicina Veterinária, área de \\ patologia. Médico e Médico Veterinário Patologista. \\ 6. Professor de Anatomia Patológica Veterinária da Escola de Veterinária da UFG - Campus de Jataí.
}

\begin{abstract}
RESUMO
Objetivo: Comparar o implante de membrana de látex da seringueira sem e com polilisina 0,1\% e tela de marlex na reparação de defeitos abdominais iatrogênicos em ratos. Métodos: Ressectou-se em bloco um segmento circular de aproximadamente três centímetros de diâmetro da parede muscular abdominal ventral de 31 ratos Wistar, preservando-se a pele. Os animais foram divididos em 3 grupos: grupo látex sem polilisina, grupo látex com polilisina 0,1\% e grupo marlex. Os animais foram sacrificados aos cinco e aos 120 dias após o procedimento cirúrgico. Fragmentos da parede abdominal foram coletados e submetidos à avaliação histopatológica. Resultados: As principais alterações observadas nos grupos tratados com as membranas de látex sem e com polilisina 0,1\% foram deiscência (21 animais) e evisceração (dois animais). A eliminação dos implantes nos grupos tratados com látex ocorreu, em média, aos 13,8 dias. Nestes animais ocorreu a formação de tecido conjuntivo fibroso, similar ao observado no grupo que recebeu o marlex. Outras alterações notadas foram aderências viscero-parietais em todos os grupos avaliados. Conclusão: A membrana de látex da seringueira com e sem polilisina a 0,1\%, quando utilizada para reconstrução de defeitos abdominais em ratos é eliminada, em média, aos 13,8 dias após a sua implantação, deixando uma base fibrosa de reparação, similar à observada após a implantação da tela de marlex.
\end{abstract}

Descritores: Próteses e implantes. Implantes experimentais. Parede abdominal. Ratos.

\begin{abstract}
Purpose: To compare seringueira latex membrane implant, with and without polilysine at $0.1 \%$ and marlex mesh on the repair of iatrogenic abdominal defects in rats. Methods: A circular segment block of approximate three centimeters of diameter was sectioned out of the ventral adominal muscle wall of 31 Wistar rats. The skin was preserved. The animals were divided into three experimental groups: only latex, latex and polilysine at $0.1 \%$, and marlex mesh. Some rats underwent eutranasia at five and some at 120 days after surgery. Fragments of abdominal wall were collected and submitted at histophatologic analysis. Results: The main alterations observed in groups treated with the latex membrane with and without polilysine were dehiscence (21 animals) and evisceration (two animals). The elimination of implant occurred at an average of 13,8 days. These animals presented fiber conjunctive tissue formation, similar to that observed in the group which received the marlex mesh. Other alterations noted were viscera-parietal adherences in all evaluated groups. Conclusion: The seringueira' s latex membrane, with or without polilysine $0,1 \%$, when used on the reconstruction of abdominal defects in rats is eliminated at 13.8 days after its implantation, leaving a fiber base of reparation, similar to that observed after marlex mesh implantation.
\end{abstract}

Key words: Prosthesis and implants. Experimental implants. Abdominal wall. Rats.

\section{Introdução}

A correção de defeitos da parede abdominal é um dos grandes problemas cirúrgicos, cuja solução ainda parece estar longe de ser encontrada. Praticamente todas as espécies animais, incluindo o homem, são susceptíveis a esta afecção, a qual causa um enorme impacto na saúde física, independente da espécie abordada. No caso 
específico de bezerras, Rabelo ${ }^{1}$ considerou que as hérnias ventrais podem interferir no desenvolvimento dos animais, diminuindo o seu valor comercial ou até mesmo conduzindo ao óbito, o que acarreta grandes prejuízos econômicos à prática da criação, com impactos sobre a economia do Estado. A eleição do procedimento cirúrgico reconstrutivo da parede abdominal deve considerar que, em geral, há perda dos diferentes planos anatômicos que a constituem. A função perdida de suporte deve ser restabelecida e, sempre que possível, a pele deve estar disponível para a cobertura total dos planos restaurados. Materiais sintéticos ou biológicos têm sido comparados ou sugeridos para uso clínico e experimental em diversas espécies. A controvérsia no que se refere ao melhor método para tratamento das hérnias é tão antiga quanto a própria doença. O material substitutivo para ser considerado ideal deve ser de baixo custo de produção, ser de fácil manipulação, promover o crescimento dos tecidos do hospedeiro, permitir que o tecido cicatricial tenha força igual ao tecido normal, ser resistente às infecções, não elucidar resposta inflamatória exacerbada, não promover a formação de aderências e fístulas e não ter suas características físicas alteradas pelos líquidos tissulares, tendo ainda que ser flexível, inerte, poroso e resistente ${ }^{2}$. Os implantes comumente utilizados na reconstrução da parede abdominal podem reunir apenas uma ou outra destas características ${ }^{3}$. Leber e col. ${ }^{4}$ salientaram que as complicações decorrentes do uso de material prostético para reconstrução da parede abdominal podem advir das propriedades físicas do implantado bem como das variações da técnica de implantação. A parede abdominal é uma estrutura dinâmica, cuja importância reside no papel fundamental que ela exerce sobre as funções respiratória e digestiva ${ }^{5}$ e as bases para sua reconstrução devem seguir os critérios de DiBello e col. ${ }^{6}$, ou seja prevenir a eventração visceral; incorporar o remanescente da parede abdominal; prover suporte muscular dinâmico; promover a aproximação livre de tensão e assegurar que a parede reconstruída tenha sua força aumentada ao longo do tempo. Material sintético implantado na parede abdominal, em contato com as alças intestinais, acarreta no risco de erosão visceral, infecção e formação de fístulas. A eliminação do implantado também pode ocorrer ${ }^{5}$. O látex da seringueira (Hevea brasiliensis) desde muito tempo é utilizado para fins industriais e, a partir de 1996, começaram as divulgações de resultados concernentes à sua aplicação como biomaterial. A literatura disponível é escassa, mas já fornece alguns elementos que permitem a avaliação do seu emprego experimental em diferentes tecidos. A biomembrana de látex da seringueira, com finalidade terapêutica foi desenvolvida por Coutinho-Netto no Laboratório de bioquímica da Faculdade de Medicina da USP de Ribeirão Preto/SP e, no ano de 1996, foi reportado o primeiro resultado da sua utilização experimental como substituto do esôfago cervical de cães ${ }^{7}$. As propriedades indutoras de regeneração tecidual da biomembrana de látex estimularam a sua utilização como substituto parcial do pericárdio de cães $^{8}$. Em trabalho experimental, os autores observaram que nos grupos nos quais este material foi utilizado, a ocorrência de aderências aos tecidos adjacentes foi menor do que no grupo controle, tendo havido regeneração completa do pericárdio subjacente à membrana de látex, com características semelhantes às do pericárdio original. Ao látex da seringueira também é atribuída a propriedade de indução da neovascularização. Existem evidências que sugeram a presença de fatores de crescimento no látex que aumentariam a vascularização local e a reepitelização de feridas conforme relataram Frade e col. ${ }^{9}$, baseados nos resultados obtidos após tratamento de úlceras cutâneas flebopáticas crônicas no homem. Neoformação epitelial semelhante ao epitélio esofágico nativo bem como neoformação muscular, porém com fibras em quantidades inferiores e menos longas foram os achados de Mrué $^{10}$, que reconstruiu parcialmente o esôfago cervical de cães com retalhos de látex com polilisina 0,1\%. Entretanto todos os animais eliminaram as próteses através do tubo digestivo. Freitas e col. ${ }^{11}$ compararam arterioplastias femorais em cães com próteses laminares de látex sem e com polilisina $0,1 \%$, com controle de veia cefálica autóloga no membro contra-lateral. Foi notada que as coberturas celulares das neoíntimas foram semelhantes entre os grupos, com maior proliferação miointimal naqueles que receberam as biomembranas de látex. Havia ainda a presença de uma matriz fibrinoconjuntiva de suporte que não foi evidenciada nos retalhos venosos. Azôr ${ }^{12}$ promoveu tratamento experimental de peritoneostomia em coelhos, com membranas de látex polimerizadas a $60^{\circ} \mathrm{C}$ e a $100^{\circ} \mathrm{C}$, relatando a ajustabilidade do implante à parede abdominal, a eliminação do implante entre o $12^{\circ}$ e o $14^{\circ}$ e a neoformação tecidual na área recoberta, sendo que os melhores resultados advieram do uso das membranas polimerizadas a $60^{\circ} \mathrm{C}$. $\mathrm{O}$ autor não relatou presença de fístula, mas por outro lado pode constatar aderências as quais foram creditadas ao contato visceral com as membranas. Rabelo e col. ${ }^{21}$ procedendo ao tratamento de hérnias umbilicais recidivantes em cinco bovinos com implante de compósito de látex com polilisina $0,1 \%$ e malha de polipropileno, puderam observar que a única ocorrência relevante no pós-operatório, foi edema local e que até a remoção dos pontos cutâneos no $18^{\circ}$ dia, as membranas permaneciam em seus sítios, sem evidências de deiscências em nenhum animal. A polilisina é uma poliamina sintética usada rotineiramente em histologia com a finalidade de facilitar a adesão celular sobre superfícies vítreas. Este produto é, carregado positivamente e as células normalmente não têm receptores específicos para ele. Acredita-se que a adsorção celular forçada pela polilisina seja promovida pelas interações eletrostáticas entre a membrana celular e a superfície da poliamina, mimetizando os eventos adesivos que ocorrem naturalmente entre as membranas celulares e seus receptores específicos. As alterações nas cargas elétricas superficiais vão assim alterar a estrutura e a função celular ${ }^{14}$. O presente trabalho teve como finalidade verificar se membranas de látex natural da seringueira com e sem polilisina seriam adequados para reconstrução da parede abdominal de ratos, tendo como comparação a tela de marlex.

\section{Métodos}

Foram utilizados 31 ratos Wistar machos e adultos, os quais foram divididos, conforme o tratamento, em três grupos (grupo látex sem polilisina - GLSP $(n=11)$, grupo látex com polilisina 0,1\%- GLCP $(n=10)$ e grupo marlex-GM $(n=10)$ e seis sub-grupos conforme o tempo de observação 
(GLSP1 (n=5), GLSP2 (n=6), GLCP1 (n=5), GLCP2(n=5), GM1 $(n=5)$, e GM2 $(n=5)$. Os animais dos sub-grupos 1 foram sacrificados aos 5 dias e aqueles dos sub-grupos 2 o foram aos 120 dias após o procedimento. Os animais foram tranqüilizados com $0,5 \mathrm{mg} / \mathrm{kg}$ de cloridrato de xilazina via muscular e em seguida foram anestesiados com Halotano em sistema aberto com vaporizador universal montado em aparelho artesanal. Os defeitos da parede abdominal foram corrigidos mediante a implantação de fragmentos de membrana de látex da seringueira sem e com polilisina $0,1 \%$ e de tela de marlex, de acordo com o grupo experimental. A fixação dos implantes às bordas da ferida muscular foi com fio de náilon $\mathrm{n}^{\circ}$ 3-0, em ponto contínuo simples. A pele foi suturada utilizando o padrão da sutura precedente. Os parâmetros avaliados durante o pós-operatório foram; edema, deiscência e/ou infecção de ferida e extrusão do implante. Findo o período de avaliação, os animais foram sacrificados por meio de super inalação de éter. Amostras da parede abdominal, incluindo os implantes foram coletadas, fixadas em formol a $10 \%$ e processadas rotineiramente para avaliação histopatológica coradas conforme técnicas de rotina, para avaliação histopatológica, sendo coradas pela hematoxilina-eosina.

Todos os procedimentos realizados obedeceram às orientações do COBEA (Colégio Brasileiro de Experimentação Animal).

\section{Resultados}

As alterações observadas no período pós-operatório (PO) foram edema moderado em todos os grupos, com duração média de cinco dias, deiscência de ferida, parcial nos animais de GM (Figura 1) e total nos de GLSP e GLCP (Figuras 2 e 3). Nos animais que receberam implantes de látex com e sem polilisina $0,1 \%$, com exceção de um animal de GLSP1, aos cinco dias em média, começou a ocorrer a extrusão do implante das bordas da ferida abdominal (Figura 4), deixando um tecido subjacente neoformado, que era bem evidenciado aos 13,8 dias, quando em média o material estava quase completamente destacado (Figura 5) ou já havia sido totalmente perdido. Apenas um animal de GLSP1 não sofreu perda do implante. Pode-se observar também drenagem purulenta em um animal de GLCP1. Dois animais de GLCP2 sofreram evisceração aos sete e oito dias de PO, respectivamente, sendo então sacrificados antes do tempo determinado. Aderências víscero-parietais foram observadas em todos os grupos (Figuras 6, 7 e 8) e em um animal de GLSP1 houve aderência ao cólon, com fistulização para cavidade pseudo-cística formada no local do implante, contendo material fecal (figura 9). As aderências foram mais intensa no grupo GLCP1. A análise histopatológica revelou que aos cinco dias, houve reação de granulação fibrovascular, com expressiva angiogênese, na face peritoneal do implante e reação granulomatosa tipo corpo estranho nas bordas da ferida nos animais dos dois grupos. Aos 120 dias a reação inflamatória crônica encontrava-se contornando a área do implante nos grupos que receberam látex (Figura 10). Ocorreu similaridade histológica entre os grupos, caracterizada pela presença de infiltrado inflamatório granulomatoso com proliferação de tecido conjuntivo fibroso, grande quantidade de macrófagos, células gigantes multinucleadas tipo Langhans e corpo estranho, linfócitos e plasmócitos de permeio, neutrófilos, eosinófilos e raros mastócitos (Figura 11).

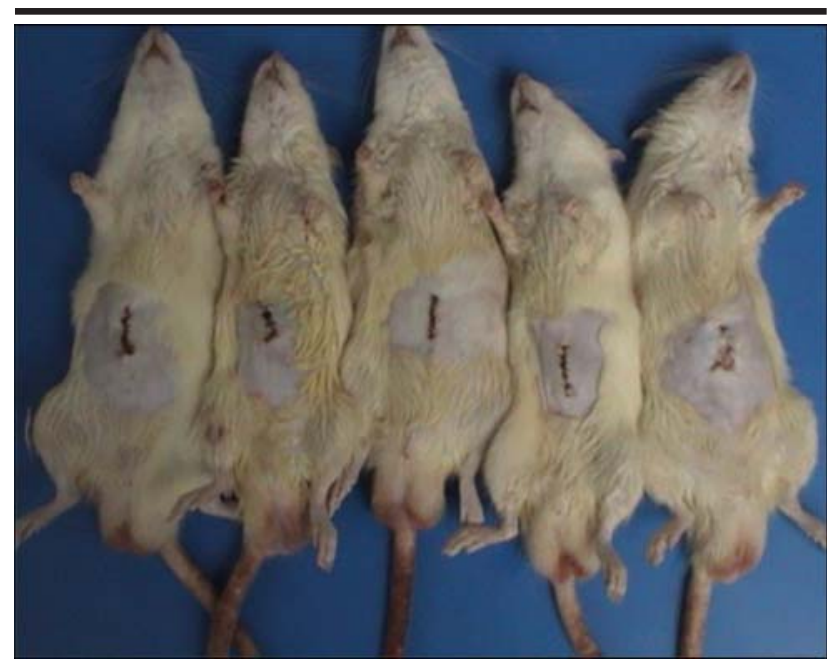

FIGURA 1 - Aspecto da ferida cutânea observado em ratos do grupo GM1.

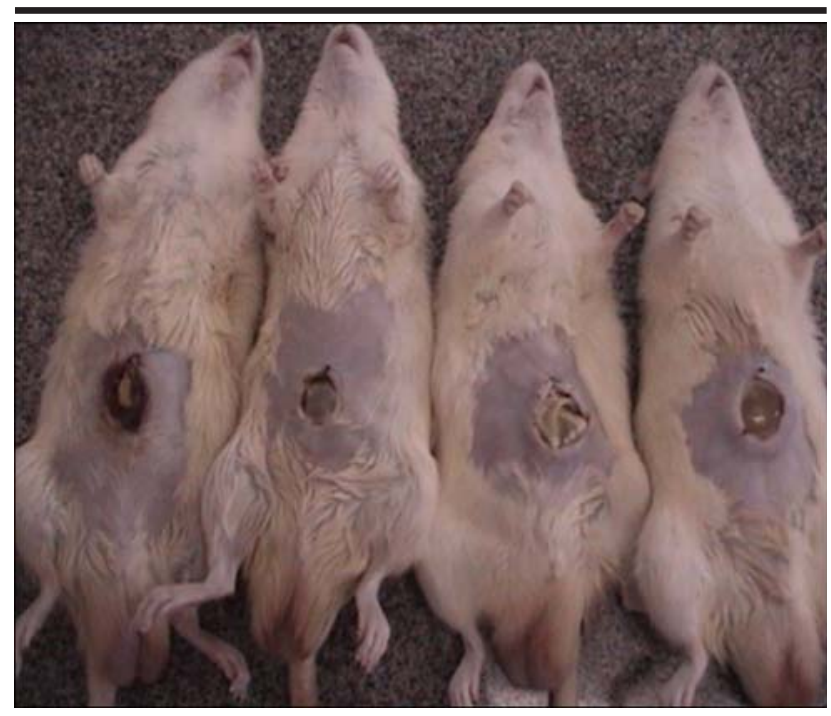

FIGURA 2 - Deiscência total de ferida cirúrgica em ratos do grupo GLSP1

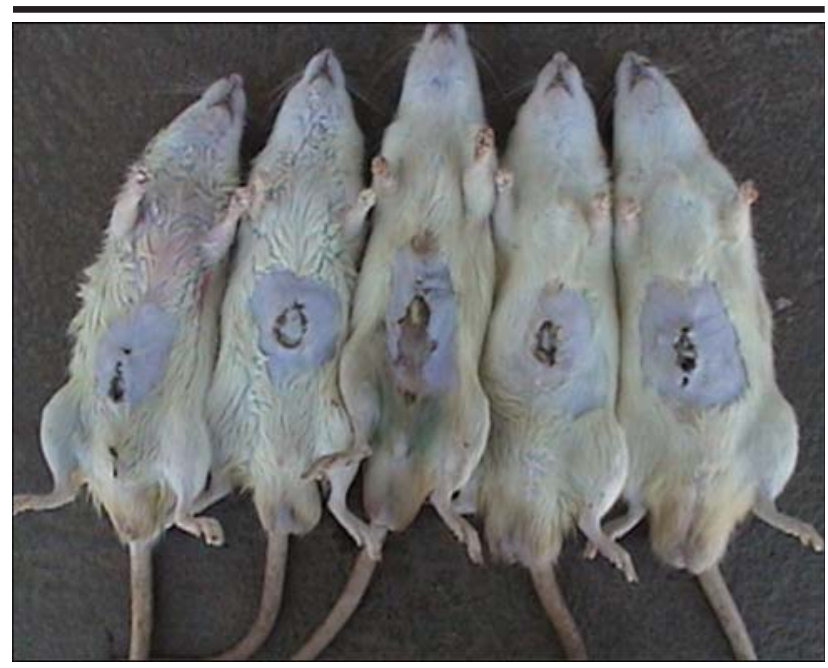

FIGURA 3 - Aspecto de ferida cutânea observado em ratos do grupo GLCP1. 


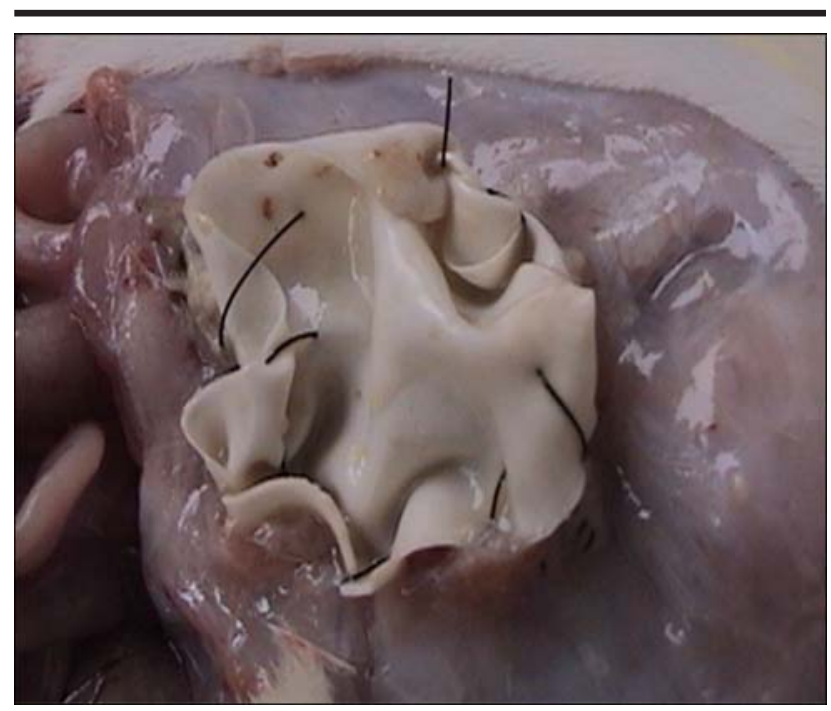

FIGURA 4 - Destacamento da membrana de látex sem polilisina, aos cinco dias do PO.

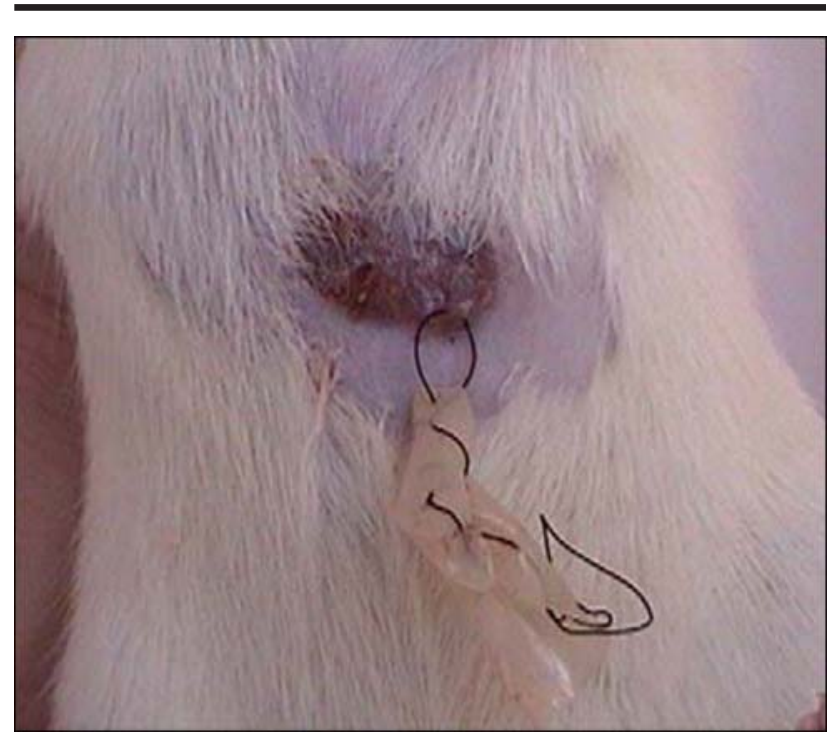

FIGURA 5 - Extrusão da membrana de látex da seringueira em média aos 13,8 dias do PO.

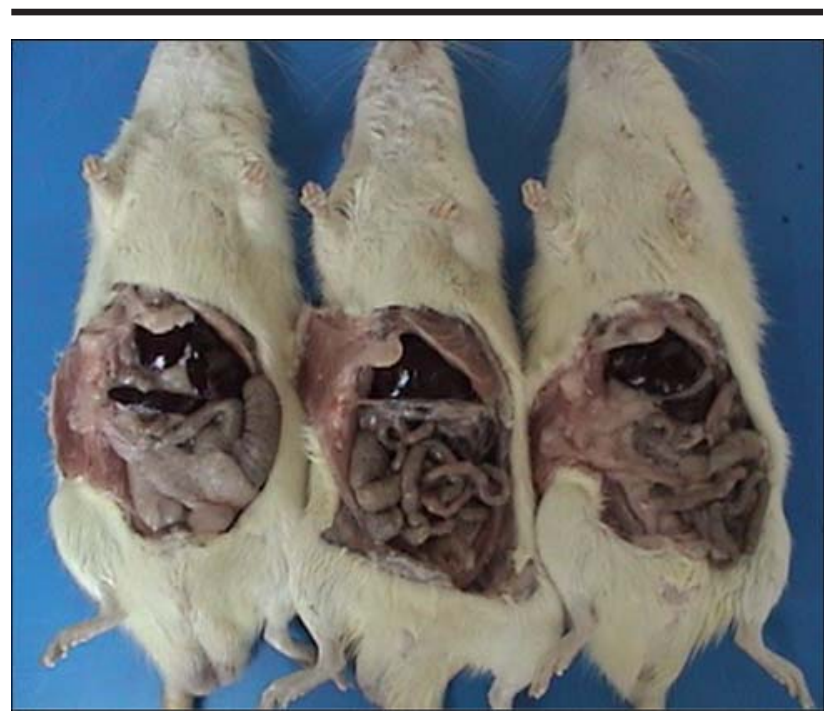

FIGURA 6 - Aderências observadas em ratos do grupo GLCP2.

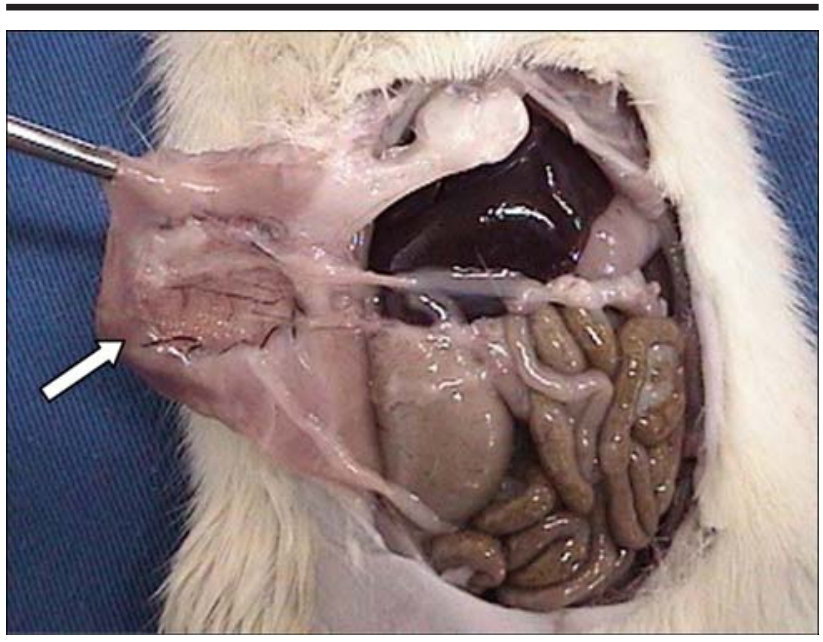

FIGURA 7 - Aderência observada em animal de GM2. Notase a presença da tela da marlex aos 120 dias (seta).

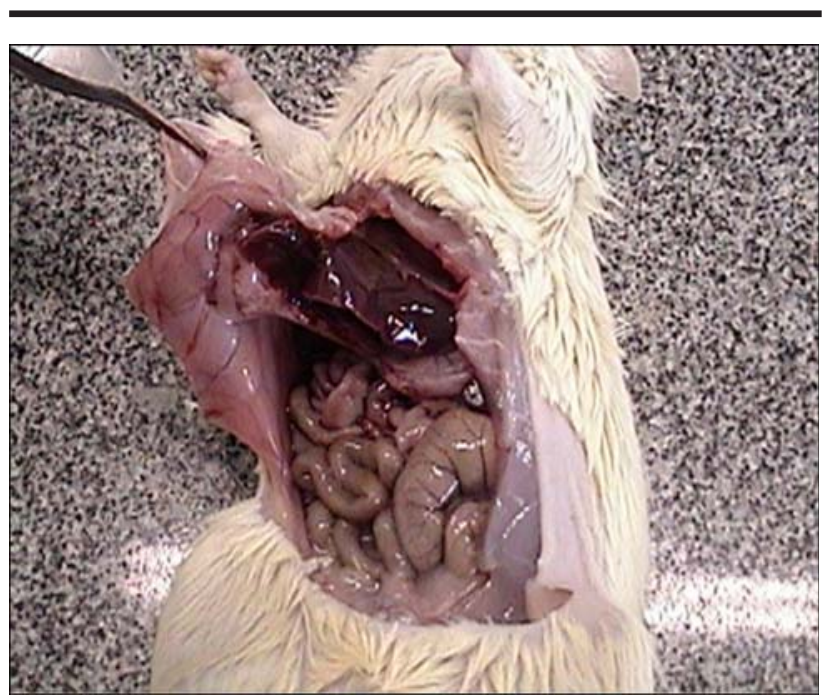

FIGURA 8 - Aderências observadas em rato do grupo GLSP1.

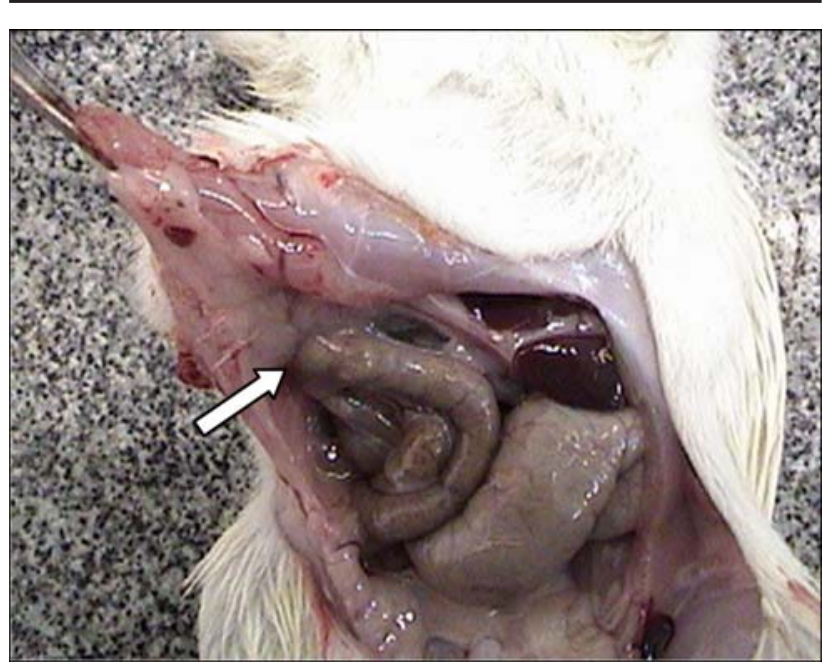

FIGURA 9 - Aderência ao cólon, com fistulização para cavidade pseudo-cística (seta) em rato do grupo GLSP1. 


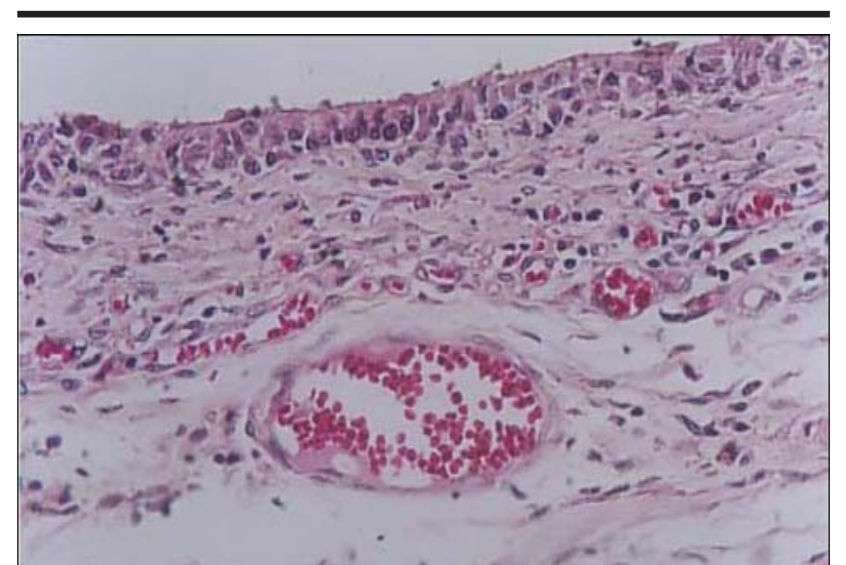

FIGURA 10 - Corte histológico de parede abdominal de rato de GLSP, aos 120 dias, mostrando neovascularização, proliferação de tecido conjuntivo fibroso e infiltrado inflamatório.

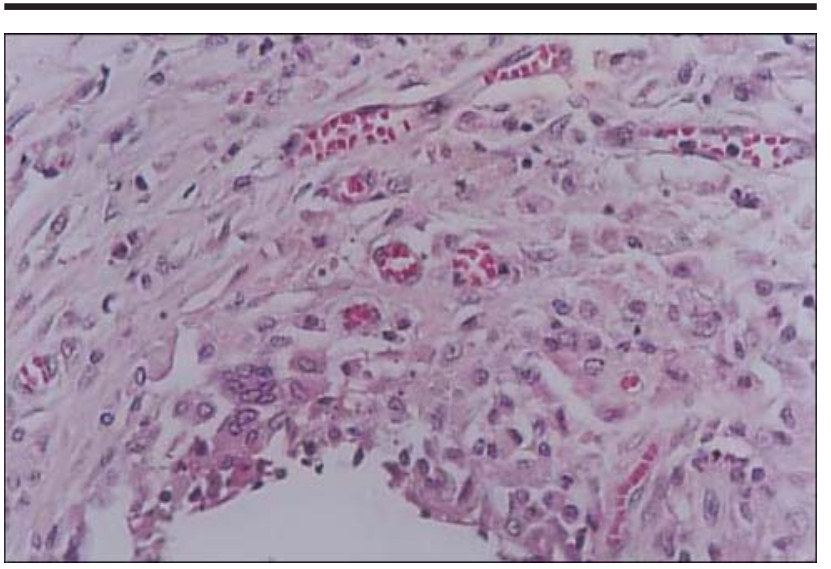

FIGURA 11 - Corte histológico de parede abdominal de rato de GM, aos 120 dias, mostrando neovascularização e deposição de tecido conjuntivo fibroso e infiltrado inflamatório.

\section{Discussão}

A despeito dos avanços nas técnicas cirúrgicas e no desenvolvimento de material de sutura e de implantes, os defeitos da parede abdominal continuam a ser um problema para os cirurgiões. Embora os materiais prostéticos sejam freqüentemente indicados, a ocorrência de infecção, extrusão e recidivas podem limitar o seu uso e não existe nenhuma técnica preventiva ou reconstrutiva universalmente aceita ${ }^{3,6}$. Quando implantes são usados para substituição fascial da parede abdominal, o processo cicatricial normal que ocorre ajuda na ancoragem do material nos tecidos. Quando uma malha não absorvível é implantada, ocorre a deposição de colágeno dentro e ao redor dos filamentos desta, resultando numa cicatriz encapsulante. Com a maturação da cicatriz há contração e distorção do e ao redor do implante, o que pode resultar em um padrão cicatricial anormal ${ }^{3}$. A incorporação do material implantado pelos tecidos adjacentes com pouca ou nenhuma reação inflamatória ou de corpo estranho, é para kama e col. ${ }^{4}$ uma das condições para que um implante seja considerado ideal. No presente trabalho foi notado que independente do material implantado, as alterações histológicas em todos os períodos avaliados, foram compatíveis com processo inflamatório granulomatoso, em função da reação do organismo frente ao implante sintético. Destaca-se também a neovascularização marcante em todos os grupos, contribuindo decididamente para a reparação tecidual, seguida de fibrose e inflamação crônica.

A comparação da tela de marlex com a membrana de látex da seringueira no presente trabalho foi em função das reportadas propriedades indutoras da neoformação tecidual do látex ${ }^{7,10,12}$, o que seria decorrente do conteúdo proteico da membrana ${ }^{12}$. Este biomaterial inicialmente atenderia algumas das condições ideais de um implante, ou seja, é de baixo custo de produção e de fácil manipulação, o que pode ser constatado uma vez que ele é flexível e se ajustou adequadamente à parede abdominal dos ratos nos quais ele foi implantado. Ele ainda apresenta uma superfície lisa e não aderente. Entretanto com o seguimento das avaliações, notou-se que o mesmo foi capaz de promover deiscências de ferida em todos os animais, ocorrendo inclusive evisceração em dois, o que não foi observado com a tela de marlex. Outro aspecto observado foi a formação de fístulas bem como a eliminação do implantado. Para Girotto e col. ${ }^{5}$ esses são achados freqüentes quando se promove a implantação de um material sintético na parede abdominal. Azôr ${ }^{12}$ referiu o não desenvolvimento de fístulas viscerais pós-cirúrgicas em coelhos que receberam implantes de membranas de látex o que não foi verificado no presente experimento, já que um animal sofreu tal processo, havendo a formação de uma cavidade pseudo-cística do cólon com a membrana. O que chama atenção na análise da literatura relativa ao látex é a discrepância de relatos quando se consideram espécies diferentes. Bovinos portadores de hérnias abdominais recidivantes tratados por Rabelo et $\mathrm{col}^{13}$ com membrana de látex com polilisina $0,1 \%$, na forma de compósito náilon, apresentaram apenas edema facilmente controlado por terapia local. Assim, o que se pode notar é que provavelmente existam diferenças entre espécies, tecidos receptores e entre a manufatura da membrana de látex, indicando a continuidade de pesquisas neste campo.

$\mathrm{Na}$ presente investigação observou-se que as membranas de látex com e sem polilisina $0,1 \%$ foram sendo eliminadas dos tecidos nos quais elas foram implantadas, a partir do $5^{\circ}$ dia do PO. A completa extrusão do material ocorreu em média aos 13,8 dias. Tal ocorrência foi relatada após a implantação do látex no esôfago de cães conduzida por Mrué ${ }^{7,10}$. De maneira similar, Azôr ${ }^{12}$ observou a eliminação do material até o $14^{\circ}$ dia PO. Em nosso estudo com exceção de dois animais eviscerados dentro da primeira semana do PO, ocorreu a formação de uma base de sustentação subjacente aos sítios implantares, constituída por tecido fibro-vascular, tão logo o material começava a se destacar, conforme mostrado na figura 5. Este tecido deu sustentação à parede abdominal e até 120 dias não houve ocorrência de hérnias.

Com relação à formação das aderências, comumente observadas após manipulação da parede abdominal, estas podem ser o resultado da isquemia local causada pela injúria mecânica. Os implantes têm sido ainda associados à irritação focal das vísceras abdominais. Estas aderências “implanteinduzidas” ocorrem numa alta incidência devido à reorganização do mesotélio e em animais a ocorrência destas 
aderências pode ser superior a 90\%, o que pode ainda estar associada a fístulas e erosões intestinais ${ }^{3}$. A presença de aderências foi significativa em todos os grupos tratados, mas destacou-se em importância nos animais do grupo tratado com o látex com polilisina 0,1\%. Infelizmente não se encontrou na literatura pertinente ao látex com finalidade terapêutica, justificativa para a adição da polilisina a este material. O mais provável poderia ser a exploração da propriedade de promoção da adesão celular forçada, inerente da polilisina, cuja superfície é positivamente carregada, reorientando assim as cargas elétricas superficiais da membrana celular. Embora não se tenha respaldo na literatura consultada, esta poderia ser a explicação mais adequada para a formação de importantes aderências nos grupos tratados com látex acrescido de polilisina $0,1 \%$.

\section{Conclusão}

A membrana de látex da seringueira com e sem polilisina $0,1 \%$, quando usada para reconstrução da parede abdominal de ratos, permite a formação de tecido conjuntivo fibroso de reparação, similarmente ao observado quando se utiliza a tela de marlex, sofrendo extrusão, em média, aos 13,8 dias após a sua implantação.

\section{Referências}

1. Rabelo RE. Emprego do centro tendíneo diafragmático homólogo conservado em glicerina a $98 \%$ e em glutaraldeído a 4\% como implante para hernioplastias umbilicais recidivantes em bovinos [Dissertação Mestrado]. Universidade Federal de Goiás - Escola de Veterinária; 2003.

2. Cerise EJ, Busuttil RW, Graighead CC, Ogden II WW. The use of mersilene mesh in repair of abdominal wall hernias. Ann Surg. 1974;181: 728-34.

3. Prevel CD, Eppley BL, Summerlin DJ, Jackson JR, McCarty M, Badylak SF. Small intestinal submucosa: utilization for repair of rodent abdominal wall defects. Ann Plast Surg. 1995; 35: 374-80.

4. Leber GE, Garb JL, Alexander AL, Reed WP. Long-term complications associated with prosthetic repair of incisional hernias. Arch Surg. 1998; 133:378-82.
5. Girotto JA, Chiaramonte M, Menon NG, Singh N, Silverman R, Tufaro AP, Nahabedian M, Goldbeg NH, Manson PN. Recalcitrant abdominal wall hernias: long-term superiority of autologous tissue repair. Plast Reconstr Surg. 2003; 112:106-14.

6. DiBello JN, Moore JH. Sliding myofascial flap of the rectus abdominus muscles for the closure of recurrent ventral hernias. Plast Reconstr Surg. 1996; 98: 464-9.

7. Mrué F. Substituição do esôfago cervical por prótese biossintética de látex. Estudo experimental em cães [tesemestrado]. Universidade de São Paulo-Faculdade de Medicina de Ribeirão Preto; 1996.

8. Sader SL, Coutinho-Neto J, Barbieri Neto J, Mazzetto AS, Alves JR P, Vanni JC, Sader AA. Substituição parcial do pericárdio de cães por membrana de látex natural. Rev Bras Cir Vasc. 2000; 15 [serial on line]. Disponível em URL: [http://www.scielo.br/acb].

9. Frade MAC, Valverde RV, Assis RVC, Coutinho-Neto J, Foss NT. Chronic phlepathic cutaneuous ulcer: a therapeutic proposal. Intern j Derm. 2001; 40: 237-40.

10. Mrué F. Neoformação tecidual induzida por biomembrana de látex com polilisina. Aplicabilidade na neoformação esofágica e da parede abdominal [tese-doutorado] Universidade de São Paulo-Faculdade de Medicina de Ribeirão Preto; 2000.

11. Freitas, MAS. Avaliação da prótese de látex natural como remendo em arterioplastias femorais. Estudo experimental em cães. [tese-doutorado] Universidade de São PauloFaculdade de Medicina de Ribeirão Preto; 2001.

12. Azôr AF. Tratamento de peritoniostomia com biomembrana de látex natural-Estudo experimental em coelhos. [tese-doutorado] Universidade de São PauloFaculdade de Medicina de Ribeirão Preto; 2004.

13. Rabelo RE, Paulo NM, Silva LAF, Lima CRO, Viu MAO, Fernandes JJR, Romani AF, Damasceno AD, Alves CB, Silva MAM. Emprego da biomembrana de látex natural com polilisina a $0,1 \%$ na hernioplastia umbilical recidivante em bovinos leiteiros. Braz J Vet Res Anim Sci. 2004; 41: 233-4.

14. Rainaldi G, Calcabrini A, Santini MT. Positively charged polymer polylysine-induced cell adhesion molecule redistribution in K562 cells. J Mat Sci Mat Med. 1998; 9: 755-60.

\section{Correspondência:}

Neusa Margarida Paulo

Escola de Veterinária

Universidade Federal de Goiás

74001-970 - Goiânia - GO

nmp@vet.ufg.br
Conflito de interesse: nenhum Fonte de financiamento: nenhuma

Recebimento: 09/03/2005

Revisão: 12/04/2005

Aprovação: 17/05/2005

\section{Como citar este artigo:}

Paulo NM, Lima FG, Juarez Júnior TS, Fleury LFF, Sant’ Ana FJF, Borges AC, Telles TC. Membrana de látex da seringueira (Hevea brasiliensis), com e sem polilisina a 0,1\% e tela de marlex na reconstrução de defeitos iatrogênicos da parede abdominal de ratos. Acta Cir Bras. [periódico na internet] 2005 Jul-Ago;20(4). Disponível em URL: http://www.scielo.br/acb

* Figuras coloridas disponíveis em $\underline{\text { http://www.scielo.br/acb }}$ 